Pro-Fil (Special Issue) 2021: 78-91

https://doi.org/10.5817/pf21-3-2425

\title{
REVISITING SOLARIS: ENCOUNTERING OTHERNESS AND THE LIMITS OF REPRESENTATION
}

\author{
MONIKA ANNA SLAWKOWSKA-RODE
}

Author and independent editor, Warsaw, Poland, monikaslawkowskarode@gmail.com

\section{MIKOLAJ SLAWKOWSKI-RODE}
Department of Philosophy of Culture, Faculty of Philosophy, University of Warsaw, Poland, Blackfriars Hall, University of Oxford, United Kingdom, m.slawkowski-rode@uw.edu.pl

RESEARCH PAPER - SUBMITTED: 20/10/2021 - ACCEPTED: 21/11/2021

\begin{abstract}
One of the core themes of Stanisław Lem's 1961 novel Solaris is the encounter with radical otherness. The ocean planet being studied by scientists form earth is usually interpreted as a representation of radical otherness, which eludes human efforts of understanding. In this paper we argue that in Solaris Lem attempts to show not merely that the ocean is unknowable, but that the unknowability is itself impossible to adequately conceptualise and represent. However, we further argue that this impossibility is the subject of an experience in which the presence of otherness is made available. We focus on the images of chaos which Kelvin discovers on Solaris to show that Lem presents the epistemic situation of the main protagonist as radically unstable. Contrary to most interpretations, however, we argue that the discursive narration in the novel engages with the presence of otherness only superficially. Rather, we suggest that the encounter with otherness is shown as something that manifests itself in bodily emotions, and is, therefore, only possible to convey non-discursively. The fear and dread inspired by the vastness and strangeness of the ocean are always presented by appeal to sensuality and bodily experience. These emotive reactions to encounters with otherness subvert its conceptual representations. We suggest that in this way Lem attempts to convey what cannot be discursively described, or even depicted. He presents radical otherness as something impossible to represent conceptually but offers a vision of the possibility of an encounter with otherness through bodily emotions. On this interpretation Solaris is not only a novel about the encounter with otherness, but also about the very possibility of representing such an encounter.
\end{abstract}

Key Words: alien; encounter; experience; limits of knowledge; liminality; otherness; representation; self

The core theme of Stanisław Lem's 1961 novel Solaris is the encounter with radical otherness, represented by the ocean planet which eludes systematic study or attempts of contact. The way in which Lem engages with this theme is complex and sophisticated, and, characteristically for Lem, also involves an awareness of, and critical engagement with, the medium he is working in. Many commentators treat the novel as "meta science-fiction" and interpret it as 
an exploration of the possibilities the genre itself affords ${ }^{1}$. This interpretation seems justified in light of Lem's own interest in the capacity of science fiction to address problems that are difficult or impossible to otherwise adequately conceptualise or represent (see Lem 1981). In the case of Solaris, however, this exploration is arguably taken further than elsewhere in Lem's writing, as Solaris interrogates the limits of conceptualisation and representation tout court. However, the book is not an illustration of a given idea about these limits or the possibility of encountering radical otherness. Rather, as we will argue, the narrative structure of the novel itself is a way of addressing the issue of otherness, and the possibility of encounter.

This paper shows that, by using literary means, Lem uncovers a new and interesting way of seeing the dynamic between the self and the other, and the idea of radical otherness. This perspective requires Lem to explore the limits of the medium he is working in. ${ }^{2}$

We argue that in Solaris Lem attempts to show not merely that Solaris is unknowable, but that the unknowability is itself impossible to adequately conceptualise and represent. Lem demonstrates this by building the narrative structure on the paradoxical impossibility of representing the limits of representation. The novel conception of otherness and the possibility of contact which emerges is, therefore, not something that can easily be translated into a different medium. For this reason, the foregoing interpretation will almost exclusively appeal to Solaris itself and mention secondary sources only when their conclusions correspond to our own. Our goal is not to contest existing interpretations but to offer a new path into understanding the significance of Lem's alien.

\section{The approach}

The cognitive relationship human beings have with the ocean planet Solaris has many dimensions. The context in which this relationship is played out is of crucial importance for understanding the picture of otherness Lem presents us with. The plot begins in medias res. We find Kelvin on the transit station Prometheus on the last leg of his voyage to Solaris. The description of this voyage provides a detailed picture of the relationship he has with the outside world.

"Don't worry about a thing. The Station'll bring you in," (Lem 2017, 4) says Moddard a member of the transit ship's crew. Indeed, Kelvin is merely a passive witness to everything that happens around him along his journey to Solaris. In fact, the whole process is presented as comically bypassing human agency. As Kelvin reports after entering the capsule "my space suit filled with air and from that point on I couldn't make the slightest movement" (Lem 2017, 4). This is a radical departure from the way Lem usually portrays his characters who explore the universe. Both Ijon Tichy and Pirx, for example, are depicted as very competent and proactive individuals who are full of initiative and engaged in their actions ${ }^{3}$. The contrast with Kelvin does not merely mark a difference in narrative structure, but more importantly emphasizes the difference in the picture of the human place in the universe which the structure conveys.

Kelvin's passivity leads to disorientation as he is not able to follow even the most obvious and significant stages of the journey. His body reacts inadequately to what happens to him, as when he tenses up in anticipation of a sudden jolt when the capsule lifts off. However, the jolt never comes, and, in the end, Kelvin misses the moment of take-off altogether. He has to take the

\footnotetext{
${ }^{1}$ See for example Rose (1981, 82-95), Suvin (1970, 212-223), Ketterer, (1974, 182-202), and Potts (1979).

2 See Jarzębski (undated) and Płaza $(2006,386)$.

${ }^{3}$ See Lem 2016, and Lem 2019.
} 
flight controller's word that the journey has begun. Kelvin's detachment and lack of bearings is pressed almost ostentatiously:

I tried in vain to spot Alpha Aquarii, towards which the Prometheus was now headed. The sky in this part of the Galaxy meant nothing to me; I didn't know a single constellation, and all I saw through the porthole was glittering dust. (Lem 2017, 4)

Given that later in the novel it is revealed that Kelvin underwent several weeks of training on Earth and given the extensive knowledge of solaristics he claims to have, his inability to identify "a single constellation" is conspicuous to say the least. Similarly, during the landing sequence Kelvin observes that "if it weren't for the numbers flashing on the gauge, I wouldn't have been aware of the speed of my descent" (Lem 2017, 5).

Kelvin's situation throughout the approach to Solaris suggests at least two things about his epistemic position. Firstly, the value and efficacy of direct experience seem to be undermined. Kelvin seems to rely exclusively on second-hand knowledge to orient himself and discern the circumstances he is in. What he is able to identify are the technical elements of the station which are presumably familiar to him, even though he sees the station itself for the first time (Lem $2017,6)$. The familiar, however, is only a speck silhouetted against "the expanse of the planet rising vertically like a wall, stripped with dirty lilac-coloured and blackish streaks" (Lem 2017, 6). This picture of the context in which the encounter with otherness takes place is made all the stranger by the narrative structure of the novel, which takes Kelvin's first-personal point of view throughout. At least initially the reader is presented with a tension where the world is presented from the standpoint of the protagonist, even as the epistemic expediency of this standpoint is called into question. This structural device contributes to the sense of disorientation and helplessness in which we observe Kelvin at the outset.

Secondly, this disorientation and helplessness is alleviated by the reliance on automated technology. Kelvin would be unable to determine his location in space, let alone navigate his way to Solaris if it wasn't for the automated systems of his capsule and the station - "Don't worry about a thing," he is told, and indeed there is no need to. Kelvin is propelled through space without the need to interfere, or even to be aware of any of the systems or processes responsible for getting him to his destination.

Technology, and more generally empirical science which produces it, is shown as a means of circumventing the limitations of the human organism when it is up against space exploration. Not only does Kelvin blindly rely on technology to reach his destination, but all the knowledge he appeals to relies on data gathered indirectly by various instruments ${ }^{4}$. The initial attempts to study the ocean planet are all carried out by fully automated machines (Lem 2017, 16). Science and technology are shown as both removing us from directly engaging with the object of our study (and so in a way impoverishing our relationship with the outside world), and at the same time augmenting this relationship by expanding our epistemic capacities far beyond their natural capabilities.

\footnotetext{
${ }^{4}$ Perhaps for this reason solaristics is sometimes taken to be an allegory of empirical science in general (see Płaza 2006, 380). This generalisation seems to be unwarranted, however. Firstly, scientific knowledge and the technology it produces even in the confines of the narrative structure of the novel does seem to be effective and accurate outside of the special case of the encounter with the ocean planet. Secondly, all of the humbling shortcomings of solaristics are connected with the encounter with radical otherness, and so with exceptional rather than usual circumstances. If Lem's book is a commentary on empirical science at all, it is, therefore, more plausibly a commentary on the limits of its application rather than its flawed nature. This interpretation is consistent with the otherwise very positive assessment of the scientific world view present in Lem's other works.
} 
However limiting science may be, it appears as an indispensable tool for expanding human knowledge. The mediated contact it affords with the surrounding world seems like second nature to Kelvin, who does not suffer from an iota of anxiety notwithstanding his lack of control and disorientation throughout his descent to Solaris. All this, however, changes radically when Kelvin reaches the space station. All his preconceptions turn out to be comically inadequate, and the sum of research carried out on the ocean planet grotesquely uninformative.

\section{Inhuman science}

The process of gathering of even the most basic data on the ocean planet is already something that poses some of the most fundamental difficulties for empirical science. We read that: no "experiment could ever be replicated"; "it was never possible to produce the same reaction to a stimulus twice" (Lem 2017, 20); "[The ocean] played an active part in the design of the devices [...]. It modified certain components of the equipment lowered into it, as a result of which the discharges it registered would change" (Lem 2017, 19). In the end, Kelvin summarises that "that which we knew in detail contained nothing but contradictions" (Lem 2017, 21).

Scientific knowledge about Solaris, therefore, is in reality non-existent, since the "legions" of scientists studying it are unable to communicate with one another and end up producing inconsistent and often contradictory theories. The Solaris station too presents itself as an antithesis of a scientific facility from the moment of Kelvin's arrival. Although from the outside its clean geometric forms inspire the same confidence as the technology which facilitated Kelvin's journey did, the inside of the station suggests a very different picture of the scientific enterprise.

The security of automated processes is replaced by chaos which looks like a sort of organic sprawl: the creeping "bundles of pipes" and the "cigar of the capsule, empty as a burst cocoon" vividly connote some sort of organic growth and decay. "A strong, unpleasant odour filled the air". Moreover the whole station is littered with objects that seem to have lost their specific functions to become mere heaps of matter: various containers, cylinders and crates form "disorderly piles", the corridors are filled with a jumble of "technical instruments", "torn papers", "dust-covered thermos flasks", "books", "glasses with a dried residue at the bottom", "rolls of white telegraph paper", and all sorts of "trash" (Lem 2017, 7). This disorder is evocative of the dissolution of the scientific framework in which everything is categorised according to a rationally imposed schema, and a return to some primeval amorphousness which precedes it.

This dissolution pertains also to the inhabitants of the station. The first person encountered by Kelvin - the cybernetician Snaut - is portrayed in a way that is symptomatic of this: he appears as "a small, scrawny man with a sunburned face", skin is "peeling off from his nose and cheekbones", "gray hair on his flat chest" is poking through the mesh shirt he is wearing, he has "bloodshot eyes", the back of his neck is "crisscrossed with wrinkles deep as cuts". There is a scent of alcohol about him, and he appears drunk. In the context of a couple of detached descriptions like "Gibarian's second-in-command" and "a cybernetician", the amount of animalistic, organic images which appeal to direct experience rather than Snaut's role or rank seems overwhelming (Lem 2017, 8-9).

This intensifies the sense of disorientation which accompanied Kelvin on the approach. He is immediately taken out of the sphere of familiar facts and procedures that organise the world and resigned to raw first-personal experience in which his surroundings appear to be chaotic and unstructured, but simultaneously oppressively inescapable. With the disappearance of the epistemic stability and security from the phenomena being studied that science and technology 
provide, Kelvin is no longer able to remain calm and detached, and begins to feel anxiety (transferred as it were from Snaut) about his situation (Lem 2017, 9).

The contrast between the approach and the reality of the station encountered by Kelvin suggests at least two further things about the context in which the particular epistemic difficulty represented by Solaris arises. Firstly, technologically advanced science doesn't merely alleviate the disorientation and inadequacy of the senses, but also removes the subject from the process of generating knowledge. This drives a wedge between knowledge and experience. It is no coincidence that solaristics is a curiously "inhuman" science in the sense that it tends to endemically exclude human agents: throughout the book the solarists do not even attempt to leave the station with the notable exception of Kelvin's visit to the surface at the end of the novel. However even "the first attempts at contact employed special electronic devices" (Lem 2017, 19), and the first mission was unable to land so "it launched into equatorial and polar orbit a number of unmanned observer satellites" (Lem 2017, 16).

Secondly, it is not merely the case that automated technology augments our ability to study and understand the world, but that without the framework of empirical science, the raw data of experience is more confusing than it is informative. On his own accord, Kelvin is unable to tell what is happening, his reactions are inadequate, and he quickly succumbs to disorientation and fear. However, the problem lies not simply with the inadequacy of technological means of study at our disposal, but with the object being studied itself. The ocean planet is notoriously illusive, and systematically resists any methodology available - even claiming that much with any confidence seems unwarranted, however, as various semblances of regularity undermine the possibility of claiming even that degree of certainly.

In effect, solaristics is only able to produce a curious anti-taxonomy of the formations that it studies: extensors, mimoids, symmetriads, asymmetriads, dendromountains, vertebrids, megamushrooms, and rapidos. Although these are described in great detail, which might suggest a certain degree of exhaustiveness of the taxonomy, it turns out that "the list of forms that occur relatively regularly [...] runs to three hundred or so items" (Lem 2017, 100). Simultaneously however Kelvin remarks that the "far-fetched descriptions of configurations formed by the plasma are in all likelihood true, though usually unconfirmable, since the ocean rarely repeats its evolutions" (Lem 2017, 95-96). The question how such an extensive list of "regularly appearing" forms could be compiled, if the forms created by the ocean "rarely repeat", is left unanswered, and just contributes to the deeply paradoxical or even absurd character of solaristics.

Moreover, the descriptions of the various formations, despite seemingly being comprehensive and rich, turn out, on closer inspection, to be vacuous and completely useless. When describing a mimoid for example, after remarking that it "does nothing" during its "lazy days", Kelvin observes that "of course, it's also possible to be inside a mimoid on its 'busy' days, but at such moments visibility is close to zero", and adds that "in fact these forms cannot be perceived from close up, due to their mountainous immensity" (Lem 2017, 99). This is after he asserts that "seen from high up, a mimoid looks like a city; but this is an illusion arising from the need for any sort of analogy with something familiar" (Lem 2017, 98).

When in turn describing a symmetriad, after recalling several theories concerning its nature, and giving detailed descriptions of its forms, he says that "a human being is capable of taking in very few things at one time", and that "a symmetriad is millions, no, billions, to the $\mathrm{n}^{\text {th }}$ power, it is unimaginability itself" (Lem 2017, 103). The inability of even the most detailed descriptions to capture anything meaningful about the objects of study appears to be almost farcical. M. Geier points to this fact when in his semantic study of Lem's Solaris he writes that "the 
ocean of the planet Solaris can have no meaning [because] if language lacks an objective-meaningful point of reference, then the solid meaning of its signs appears to be a fiction also" (Geier 1992, 197, 196).

It is also in this deeper sense that solaristics emerges as a singularly "inhuman" science: instead of yielding knowledge, it creates more confusion about the object of study; in place of analytic elegance, it produces endless descriptions and systematizations with little or no epistemic value; rather than being able to give a sense of control, it contributes to a feeling of helplessness and inadequacy of the solarists. It is perhaps because of this grotesque inadequacy that the phenomena being studied appear monstrous and threatening.

The chapter in which the various formations are described is entitled "Monsters". And indeed, besides quasi-scientific descriptions Kelvin speaks about a "monster's back, a colossal python that has swallowed an entire mountain chain" (Lem 2017, 97), "a prolonged hollow roar" (Lem $2017,101)$, "a wail as if from lifeless vocal cords or monstrous throats" (Lem 2017, 105). Those observing the forms of the ocean for the first time "are staggered above all by their outlandishness and their vast scope" (Lem 2017, 96). The final stages of the collapse of the symmetriad are particularly awe inspiring and alarming to behold:

By this point the towering construction is supported only by the gale of howling from the abyss, passing through it via a thousand shafts, inflating the structure, which begins to slide downwards, collapse like a plaster statue in the flames, though here and there the last twitchings can still be seen, incoherent movements disconnected from the rest, blind, ever weaker, till the huge mass, undermined and exposed to constant attack from outside, collapses with the slowness of a mountain and vanishes in a confusion of foam like that which accompanied its titanic appearance. (Lem 2017, 105)

However, despite the ferocity of "this movement of destruction [...] the spectator is immediately overcome by a sense of utter deadness" (Lem 2017, 105).

This incongruent horrific spectacle, like the overall monstrous character of the formations, is difficult not to interpret in the same way as the similarity of a mimoid seen from afar to a city: an "illusion arising from the need for any sort of analogy". That the analogies are terrifying only emphasizes the unapproachability of Solaris, although of course this also merely reflects the attitudes of the solarists, and not the nature of the ocean planet itself. All this contributes to a fact noted by several critics that Solaris remains hopelessly out of reach throughout the novel. As Płaza points out "it is difficult to speak about the Solaris ocean as a phenomenon that is present, and itself being described in the novel, or even during direct contact" (Płaza 2006, 373 [trans. author]).

It is in this context - the context of almost comically inadequate means, and the fundamental unapproachability of Solaris - that the question of the possibility of encountering radical otherness is posed. The fact that this context is introduced in a narrative form is significant. The inadequacy of means, and the alienness of the ocean planet are not just postulated but shown as being experienced. It is the sense of absurdity surrounding the attempts of encounter which suggests that the reality of these limitations escapes simple stating. Through its narrative structure, therefore, the book can subtly suggest that any hope of encounter has to be sought beyond the confines of discursive conceptualisation. 


\section{The edges of encounter}

Is an encounter that requires us to abandon empirically founded knowledge and discursive conceptualisation at all possible, or even thinkable? Is it possible for human agents to move beyond these confines, or is the other side of the boundary they represent an illusion produced by misunderstanding their meaning? It is clear that, when the framework of empirical science is not suspended, contact is simply impossible. This, as we have seen, is one of the conclusions to be drawn from the grotesque failures of solaristics. We suggest that in Solaris Lem explores not so much how far we might be able to go towards encountering otherness by the means available to us, but rather to what degree these means might be abandoned, and the limitations they impose pushed against for the same purpose.

We already remarked on Kelvin's disorientation during the approach sequence. In fact, as he himself reports, "and once again I'd missed the crucial moment when the planet came into view. It extended vast and flat" (Lem 2017, 5). It is as though it is impossible to prepare for the encounter - indeed, given the incongruous descriptions of Solaris in the sources he is familiar with, this is unsurprising. Solaristics is simply unable to provide the kind of knowledge that enables Kelvin to identify the station upon approach. Simultaneously, however, it turns out that the station is not prepared for his arrival either. Kelvin expects someone to meet him upon arrival, but nobody comes. He then discovers with horror that no one on the station knew he was coming. In reply to questioning about Moddard's message and the information which preceded his arrival by months, Snaut mumbles "Right. Right... No doubt. It's just that here, as you can see, there's a certain amount of... confusion" (Lem 2017, 9).

Kelvin enters the chaos of the station as a place in-between the two radically different and separate worlds - his own, and that of the ocean planet - alone, and forced to depend solely on what is made available to him directly through experience. This is suggestively conveyed by the contrast in the kind of observation Kelvin makes when looking at the station orbiting above Solaris. The station itself is described with technical detail and with reference to its various functional parts. The ocean, which it is silhouetted against, is from the first glimpse portrayed by appeal to sensory impressions, and organic, or even animalistic associations:

Simultaneously I noticed the violet-flushed furrows of the ocean, which betrayed a faint motion; the clouds suddenly rose high up, their edges marked with dazzling crimson, the sky between them grew distant and flat, dull orange in color [...]. (Lem 2017, 6)

Then "everything becomes blurred" as the capsule nears the station. This sequence, which results in a blurred image, might again be seen as symbolising the inadequacy of, in this case, first personal observation. In fact, as the narration progresses, we begin to see that the observations Kelvin makes, and the impressions he has when inspecting the ocean are as far removed from their putative object as the quasi-scientific theories of solaristics.

The planet appears in the alternating light of its two suns: the red and the blue. Kelvin often describes the light emitted by the blue star in a way that suggests its intensity is an impediment to discerning anything. He speaks of a "blue fire; white sea of fire" (Lem 2017, 24-25), a "blinding glare" (Lem 2017, 41), or its "blue heat" (Lem 2017, 81). The ocean itself seems visible mostly in the "crimson glow" (Lem 2017, 13) of the other sun, in which its waves are "glinting bloodily" (Lem 2017, 10), or look like "reddened olive oil" (Lem 2017, 13), or have "bloody flecks" (Lem 2017, 25). In the red light Solaris appears like a pool of blood, or some other organic substance which is "peeling in a series of bloody contour lines" (Lem 2017, 157). Other shades which Kelvin discerns carry strong bodily connotations too: it produces "slimy foam the color of bone" (Lem 2017, 10), as well as "yellow and gray foam" (Lem 2017, 176), and "gray-green slime" (Lem 2017, 97). The adjectives ("tumescent red" (Lem 2017, 142)), 
and verbs ("violet flushed" (Lem 2017, 6)) used in the descriptions, as well as the objects being described ("gold-colored ooze" (Lem 2017, 70), "light-skinned excrescences" (Lem 2017, 98), dirty green encystment" (Lem 2017, 176)) also bring to mind various tissues or decomposing organic matter.

These descriptions, like the descriptions of the various formations of the ocean, seem inevitably to reflect the need for the analogy with something more familiar. The impenetrable otherness of the ocean is seen under the aspect of flesh - heaving, often mangled, or in various stages of putrefaction. This might be taken to express on the one hand a subconscious attempt to make familiar, or graspable, and on the other, equally, a representation of a fragmentation and distortion which makes the familiar repulsive and even alien. This effect is commented on by I. Csicsery-Ronay Jr.:

When confronted by a concrete existing thing that resists all strategies of appropriation, the common character of these strategies comes out in relief: all are projections of human qualities, as if they could exist outside human limits. (Csicsery-Ronay Jr. 1985, 16)

Both Kelvin's personal observations, and the taxonomies, and theories produced by solaristics tend to gravitate towards representations of the most familiar subject matter - the human which evokes otherness by being horrifically deformed or monstrously disproportionate. Indeed, as we learn, "it was once thought [the formations] were some sort of organs of the monster, in which it metabolizes matter or which contain processes of breathing, the transfer of nutrition, and other things now known only do dusty library shelves" (Lem 2017, 97). Indeed "every hypothesis was eventually disproved by a thousand painstaking and often perilous experiments" (Lem 2017, 97), and this being true with respect to "the simplest, and most enduring form" (Lem 2017, 97) the ocean is known to produce.

However, just as in the case of solaristics, Kelvin's observations fail completely to capture anything of what Solaris might actually be like in itself. As we have seen, the sheer scale of the phenomena being observed is prohibitive when it comes to the feasibility of adequate observation. The formations being studied by the solarists are "larger in magnitude than Colorado's Grand Canyon" (Lem 2017, 96), and "millions of which litter the vastness of the living ocean" (Lem 2017, 97); they weigh "hundreds of thousands of tones" (Lem 2017, 97), and are "larger than a terrestrial city" (Lem 2017, 98). Moreover, as the narration progresses, the colours Kelvin perceives seem to phenomenologically fade more and more into black: the ocean is described as an "inky wasteland" (Lem 2017, 67), or just an "undulating black" (Lem 2017, 142), colours give way to "the vast blackness of the ocean" (Lem 2017, 153), or "black waves" (Lem 2017, 173), and the ocean becomes an "alien, black, liquid monster" (Lem 2017, 136) slipping further out of reach of any familiar frame of reference ${ }^{5}$.

Csicsery-Ronay Jr. eventually reaches a similar conclusion as Płaza quoted above:

Of course, Lem cannot create a truly alien creature to make us see this paradox from outside human consciousness. Though he takes great pains to evoke the sense of Solaris's strangeness through vividly detailed, and yet barely intelligible, descriptions of the planet and its excrescences, we always see the planet through a human observer's language as it strives to assimilate an a priori nonassimilable object. (Csicsery-Ronay Jr. 1985, 16)

It is true that we always see the planet "through a human observer's language" but it is implausible to assume that Lem, as a mature author, didn't himself notice this fact, especially given

\footnotetext{
${ }^{5}$ E. Skibińska offers a detailed study of the frequency with which different colours appear in the descriptions of Solaris. According to her analysis black is the most frequently appearing colour in the ocean's descriptions, even given shades or red (which comes in second), but excluding references to fire and burning, which Skibińska herself, we believe wrongly, associates with redness. See Skibińska (2010, 181-182).
} 
this is a device so consciously utilised in how the narrative structure is built. We believe Lem's intention was not the creation or depiction of a "truly alien creature" at all. Rather, it seems reasonable to suppose that what Lem is interested in, given all the above, is not whether otherness might be possible to capture adequately within the confines of human epistemic means, but how far humanity is able to push the limitations of its own condition to facilitate contact.

Though it is undoubtedly true that the reader never sees the ocean "directly", without mediation of the arcane descriptions of solaristics, or Kelvin's impressions, it is not the case that Solaris is completely absent from the novel. On the contrary, a deep sense of presence haunts Kelvin from his arrival on the station - it returns to him in waves subtly connoting the movements of the ocean:

I hesitated, then pressed down lightly on the handle and slowly pushed. As it opened I had the feeling, bordering on certainty, that someone was there. I went inside. There was no one. An identical convex window, though slightly smaller, looked out onto the ocean. (Lem 2017, 13)

I felt someone's eyes on me [...]. The skin on my back and the nape of my neck began to tingle, the feeling of a hard, motionless gaze was becoming unbearable [...]. I turned around abruptly. The room was empty. In front of me there was only the gaping black of the bay window. The sensation lingered. The darkness was looking at me, amorphous, immense, eyeless, devoid of limits. (Lem 2017, 23)

I recalled how horrified I'd been at the empty gaze of the Solarian space the previous evening. (Lem 2017, 77)

When I think about it now, it seems to me that the impression of uncertainty, suspension, of the moment before an earthquake, was prompted by a presence that could not be sensed in any other way and yet filled every deck and room of the Station. (Lem 2017, 155)

I had never before been so aware of its vast presence, its powerful, inexorable silence breathing evenly through its waves. (Lem 2017, 177)

The ocean eludes the senses and is indescribable, but it inspires fear and its presence is almost constantly felt. Otherness therefore doesn't appear as something in some way being depicted but rather as a source of fear, uncertainty, and a sense of presence. The narrative of Solaris explores a liminal sphere where the human and the other may become open to each other's presence. Most commentators in fact see the change which Kelvin undergoes at the end of the book as sign that, even if wholly out of reach, the radical other exists, and that perhaps it may even be able to affect change in human beings (Csicsery-Ronay Jr. 1985, 9). The change doesn't however take place at the end of the book, but as we have tried to show, begins already with the approach sequence to the station. If there is a degree of openness between Kelvin and Solaris at the end of the book, its meaning is developed throughout the narrative, rather than being the result of a final transformation, or moment of surrender. So far, we have looked at how the ocean is depicted and perceived (or rather how the impossibility of its depiction and observation is represented), and in what circumstances the perceptions are said to take place. Let us now examine what the narrative tells us about Kelvin himself.

\section{Self and other}

The ocean and its peculiar unknowability inspire fear and a gnawing sense of disorientation. Indeed, these emotions become so intense Kelvin is nearly driven mad. However, as the novel progresses, Kelvin's insecurity undergoes an important transformation, which is analogous to the change in perspective from the objective descriptions of science to subjective observations with regard to the ocean. His anxiety is, to begin with, caused by the unnerving 
presence he feels and the chaos engulfing the station. However, the more intense the experiences he undergoes, the more his distress seems to attach to his own place in the events that unfold. This transition is shown primarily by a subtly introduced but, in reality, a deep difference in how Kelvin reacts to the emotions he experiences.

The first way in which he deals with stress and emotional pressure is by going to the library. The library, apart from being a plot device for providing exposition on the incredible theories of solaristics, serves a consolatory role. The consolation however does not come from new data that allows Kelvin to understand the phenomena he encounters better. By his own admission he consults material which he knows already:

I was filled with anticipation; the tension had grown to the point where I didn't want to have open space behind me. I decided to fight it. I moved the chair up to the shelves. I took down a book I knew only too well - the second volume of Hughes and Eugel's old History of Solaris - and started flipping through it, resting the thick, stiff spine on my lap. (Lem 2017, 15)

Books are not a source of knowledge but serve a therapeutic purpose. They reaffirm what is already known. In moments of crisis, "flipping through" passages Kelvin has rehearsed many times over produces a sense of security. He seeks comfort in the library in the most crucial moments of anxiety: when he first takes stock of the strange happenings on the station, after the unexpected meeting with the black woman, when the solarists are thinking of destabilising the neutrino systems, or after the experiment with the encephalogram, which marks the beginning of the end of the strange events on the station.

But as we have seen, the information contained in the "dusty library shelves" can hardly begin to supply a sense epistemic stability. And so, comically, the library fulfils its consoling role mainly by its mere physical presence ${ }^{6}$. The tomes are first and foremost objects with which physical contact is possible. This is signalled by the abundance of physical properties included in their descriptions: a "bulky tome" (Lem 2017, 19), "so heavy I had to lift it with both hands" (Lem 2017, 21), "a slim little leather-bound volume with tattered corners" (Lem 2017, 66), or "tomes, so heavy they made my hand droop" (Lem 2017, 95). In fact, from the first moments of Kelvin's arrival on the station he unwittingly appeals to physicality to regain a sense of normality:

The sudden rush of water felt like relief. I twisted beneath the hard, hot stream of water, massaging my body, snorting, all in a somehow exaggerated way, as if I was shaking off, expelling from myself, the whole uncertainty that filled the Station with its infectious suspicions. (Lem 2017, 14)

It is his own physicality that Kelvin appeals to when the solaristics he rehearses and the experiments he performs fail to give him grounding amongst the chaos he encounters. This is why, it seems, upon seeing the black woman he squeezes his hand "till the bones crack" (Lem 2017, 28). His reactions become progressively more extreme. During his first encounter with Harey Kelvin hits himself in the face to sober up (Lem 2017, 28). He is convinced that pain will wake him up and seems confused when striking himself doesn't work (Lem 2017, 51). To maximise the effect, he even bites his fist until it bleeds (Lem 2017, 82).

At first it might seem that Kelvin's reactions are analogous to those of a person unsure if they are dreaming - resorting to a sharp sting of pain to wake up is, in fact, what he explicitly intends. However, quickly it begins to look more like Kelvin is testing his own and not the apparition's reality. He pauses and contemplates the pain, and studies its corollaries:

\footnotetext{
${ }^{6}$ See Michałowski $(2003,334-336)$.
} 
With my foot I pulled up one of those half-melted tools lying around on the floor and picked it up with my free hand. Its tip was sharp. I held it against my skin right above the place where there was a pink, semi-circular, symmetrical scar, and I pressed it into my body. The pain was acute. I watched the blood flow in large drops down the inside of my thigh and drip quietly onto the floor. (Lem 2017, 51)

Harey and the black woman are both different than the ocean in that they are not alien, but, on the contrary, strangely familiar and life-like in a way Kelvin is increasingly prone to accept. $\mathrm{He}$ is able, triumphantly, to identify what is wrong with the black woman: her lack of odoriferous attributes (Lem 2017, 28). His assuredness as to what is real and what is not seems tested when he sees the black woman alongside Gibarian in the morgue (Lem 2017, 42). Gibarian's corpse is frozen and lifeless, yet, given the conditions, it is decidedly more reminiscent of life than the seemingly "resting" body of the black woman. Although her body is warm and mobile with the lazy sleepiness of a puppy, this strikes Kelvin as inhuman and horrifying in comparison with the frozen carcass next to it, which at least behaves like one would expect. The positive connotations of life and the negative ones of death are reversed.

His discovery of Harey's unreality is however the most shocking:

The two identical dresses were the most terrible thing of all I'd experienced till now. Harey was busy tidying the medicine cabinet. I turned away from her surreptitiously and bit my fist till it bled. Still staring at the two dresses - or rather the same dress repeated two times - I began backing towards the door. (Lem 2017, 82)

Soon after he performs the experiment, which reveals that Harey's existence is only apparent:

This body, seemingly so slender and frail - in fact indestructible - at its deepest level had turned out to be made of nothingness? [...] I'd gone down through all the stages, cells, protein conglomerate, molecules, and they looked exactly as they had on thousands of slides I'd seen. But the last step downwards led nowhere. (Lem 2017, 86)

However, Kelvin is drawn to Harey instinctively, not rationally - he follows the impulses and emotions which originate in his body:

My body was acknowledging her, wanting her, drawing me to her beyond reason, beyond argumentation and fear. (Lem 2017, 52)

[...] but a moment later, without seeing I put my arms around her slender back and when I felt it tremble, I suddenly believed in her. (Lem 2017, 81)

Kelvin's disposition to accept these apparitions is surprising and terrifying to him but cannot be assuaged by appeal to any theory or the strength of evidence. It seems that this is because the G-formations don't so much undermine his sense of the reality of the external world - in a way he could perhaps wake up from, or rationally reaffirm - but that of his own reality. Since the phenomena pertain to his very subjectivity, Kelvin tries to seek refuge in seeing himself as an object (pain, harm and the destruction of tissue). Even the reactions of fear and incredulity which he at first tried to keep at bay, now have to be prompted by physical stimulus - stimulus that reminds him that his own presence is not empty, as that of the G-formations. Slowly, he draws nearer to the liminal sphere otherness opens before him and away from the safety of recognisable categories, and finally discovers the ocean's presence within himself:

Yet it had entered into me, I have no idea how; it had sifted through my entire memory and found its most painful atom. How could that be doubted? And without any assistance, without any "radiation transmission" it had broken through the double hermetic plating, the thick armouring of the Station, had found my body inside it, and had made off with its plunder... (Lem 2017, 136) 
This discovery allows him, in turn, to approach the ocean:

Staring in wonderment, I was descending to regions of inertia that might have seemed inaccessible, and in the gathering intensity of engrossment I was becoming one with this fluid unseeing colossus, as if - without the slightest effort, without words, without a single thought - I was forgiving it for everything. (Lem 2017, 177)

Kelvin becomes open to and accepts the presence of Solaris, but this presence is not what he was hoping to find at all. In fact, we may say that he discovers that this presence is an "empty presence". Something that escapes all the categorical frameworks we may appeal to, and something that is obscured by the very efforts of encountering it. Indeed, the very idea of the other as opposed to the self as the object of that encounter emerges as a limitation which impedes the encounter. This limitation is slowly overcome as the way Kelvin sees the ocean planet evolves from associations with flesh and organic matter, which exhibits volition, and perhaps intentionality, through an inanimate object, or a structure being studied, to an empty, bare presence. Solaris is, in the end, nothing to the subject studying it. In order to acknowledge and approach its inexplicable presence, paradoxically perhaps, subjectivity itself has to be shed. In the liminal space which is thus created, contact doesn't so much occur, as both the self and other silently fade into each other, as the eerily serene thoughts Kelvin has at the end of the book suggest.

This picture of the relationship between subjectivity and otherness has far reaching implications. First, we might observe that the outcome is not as pessimistic as the idea of radical otherness represented by the ocean planet might at first suggest. Possibilities of encountering otherness, however, are only appendant upon at least a partial resigning of the self. Second, if the very notion of the other is already an imposition of the self on the phenomena it encounters, then this gives new grounds for critical engagement with conceptions of subjectivity which depend on its relation to otherness. If the above interpretation is granted, Solaris might be seen as a form of such engagement. The picture of the self which emerges is not one which stipulates the dependence of the self and self-awareness on otherness, but on the contrary its insular character which impedes any form of contact by subsuming everything it encounters into its own sphere.

\section{Conclusion}

We have tried to show that Lem's Solaris is not so much a dramatization of the problem of unknowability of radical otherness, as is assumed by most commentators, but rather that it tries to convey the impossibility of even representing the problem. For to purport to represent the problem adequately is already to undermine the radical character of otherness. This difficulty, if unrecognised, may invite a superficial sense that we are able to nonetheless get some purchase on radical otherness - even if merely in terms of its unknowability. This arguably is the trap many commentators themselves fall into, and which Lem depicts with the absurd spectacle of solaristics. Lem, we have argued, dramatizes the impossibility of representation itself, and offers a contemplation of what this impossibility entails for the possibility of contact. Given this difficulty Lem addresses the issue not so much in what the book depicts but in how the narrative structure unfolds.

First, as we have shown, Lem presents the epistemic situation of the protagonist seeking contact as radically unstable. This is conveyed by Kelvin's simultaneous reliance on automated technology, and its utter uselessness in the attempts of encounter, by the chaos and disorientation surrounding Kelvin's arrival on the station, by the farcical account of solaristics, and by the organic connotations evoked by the ocean's formations, which both affix some familiarity to them, but by disfiguring the familiar, make it monstrous. Furthermore, as the narration progresses, and Kelvin becomes more and more personally involved in what is happening on the 
station it becomes clear that his very subjectivity is an insurmountable obstacle, as the ocean is no more an object for his subjectivity to engage with, that the G-formations are what they appear to be.

However, we suggest that all this does not merely imply that the possibility of contact is an illusion. Rather the impossibility of getting a purchase on radical otherness is itself the subject of a form of experience in which the presence of otherness is made available. The experience in question is predicated on emotive states, but understood not as forms of judgement, but rather as bodily emotions. As such they bring into focus, and to a degree push against the limits of our embodied subjectivity. If this is right then Solaris is not so much a literary exploration of how far we might be able to venture, by the means available to us, towards encountering otherness as it is an exploration of how far the limitations appendant on these means might be possible to recognise and accept, as Kelvin eventually does. Once they have been, Lem seems to suggest, a liminal space pervaded by the presence of otherness opens up.

\section{Acknowledgements}

This research was supported by the University of Oxford project 'New Horizons for Science and Religion in Central and Eastern Europe' funded by the John Templeton Foundation. The opinions expressed in the publication are those of the author(s) and do not necessarily reflect the view of the John Templeton Foundation.

\section{Bibliography}

Csicsery-Ronay Jr., I. (1985): The Book Is the Alien: On Certain and Uncertain Readings of Lem's “Solaris", Science Fiction Studies, 12(1), 6-21, available at:

$<$ https://www.jstor.org/stable/4239658 >.

Geier, M. (1992): Stanislaw Lem's Fantastic Ocean: Toward a Semantic Interpretation of "Solaris", Science Fiction Studies, Vol. 19, No. 2, 192-218, available at:

< https://www.jstor.org/stable/4240151 >.

Jarzębski, J. (undated): Lustro [online], [accessed 2021-09-12]. available at: < https://solaris.lem.pl/ksiazki/beletrystyka/solaris/30-poslowie-solaris $>$.

Ketterer, D. (1974): New Worlds for Old, Indiana University Press.

Lem, S. (1981): Metafantasia: The Possibilities of Science Fiction, Science Fiction Studies, 8(1), 54-71, available at: < https://www.jstor.org/stable/4239383>.

Lem, S. (2017): Solaris [e-book], Pro Auctore Wojciech Zemek.

Lem, S. (2019): Tales of Pirx the pilot, Penguin Classics.

Lem, S. (2016): The Star Diaries, Penguin Classics.

Michałowski P. (2003): Babel XXI wieku, in Jarzębski, J. - Sulikowski, A. (eds.): Stanisław Lem: pisarz, myśliciel, człowiek, Wydawnictwo Literackie.

Płaza, M. (2006): O poznaniu w twórczości Stanisława Lema, Wydawnictwo Uniwersytetu Wrocławskiego.

Potts, S. J. (1979): Dialogues Concerning Human Understanding: Empirical Views of God from Locke to Lem, in Slusser, G. (ed.): Bridges to Science Fiction, Southern Illinois University Press.

Rose, M. (1981): Alien Encounters, Harvard University Press. 
Skibińska, E. (2010): Kolory Solaris we francuskim przekładzie, in Skibińska, E. - Rzeszotnik, J. (eds.): Lem i ttumacze, Księgarnia Akademicka.

Suvin, D. (1970): The Open-Ended Parables of Stanislaw Lem and "Solaris", in Lem, S.: Solaris, Berkley. ply to works or elements (such as images or photographs) that are used in the work under a contractual license or exception or limitation to relevant rights. 